\title{
Impact behaviour of bombyx mori silk fibre composite face-sheet sandwiched coremat
}

\begin{abstract}
This paper describes the result of an experimental investigation on the impact damage on Bombyx mori woven natural silk/epoxy composite face-sheet and Coremat core sandwich panel. The test panels were prepared by hand-lay-up method. The lowvelocity impact response of the composites sandwich panels is studied at three energy levels of 32,48 , and 64 joule respectively. The focus is to investigate damage initiation, damage propagation, and mechanisms of failure. It was observed that absorption energy capability decreased as impact energy increased. There was deflection on each impact load configuration at some point but their margin was insignificant. Physical examination of the specimen show that damage areas increased with increase in impact load. The novelty of this research is the use of Bombyx mori woven natural silk fabric as a reinforcement fibre.
\end{abstract}

Keywords: natural silk fibre, sandwich, impact energy attenuation, composite
Volume 4 Issue 2 - 2018

\author{
Ude AU,' Azhari $\mathrm{CH}^{2}$ \\ 'Department of Mechanical, Energy and Industrial Engineering, \\ Botswana International University of Science and Technology, \\ Botswana \\ ${ }^{2}$ Department of Mechanical and Materials Engineering, Faculty \\ of Engineering \& Built Environment, The National University of \\ Malaysia, Malaysia \\ Correspondence: AU Ude, Department of Mechanical, Energy \\ and Industrial Engineering, Faculty of Engineering, Botswana \\ International University of Science and Technology, Private Bag \\ 16 Palapye, Botswana, Tel +60162843058, Email \\ albertuche@yahoo.com
}

Received: February 22, 2018 | Published: March 12, 2018

\section{Introduction}

Structural sandwich composite fabrication involves a number of layers of different materials, most often, but not exclusively, made of two identical thin and stiff skins, separated by a thick, lightweight and relatively weak core, bonded together with layers of adhesives. The structural concepts of any sandwich structure is made in a way that, the skins primary objective is to resist the in-plane and bending loads, with top side skin in compression and bottom side in tension. The core then corresponds to the web, which carries the transverse shear stresses and increases the stiffness of the structure by keeping the skin apart. ${ }^{1}$ The demand of sandwich structures has increased in many industries including, transportation and automotive, sports, aerospace and renewable energy in recent years. Superior structural ability to carry transverse loads, high stiffness, low weight ratio, excellent thermal insulation and acoustic damping are some of the properties which endeared sandwich composites to these industries. Structural members using sandwich construction are designed usually in terms of flexural stiffness and strength. However, some structures most are capable of sustaining large overloads, (e.g.): foreign object impact or impact with solid objects. In these cases, the non-linear (post-failure) behaviour of the structure is important and parameters of interest are the integrity of the structure before total collapse occurred..$^{2-5}$

The complexity of composites structures and its susceptibility nature under impact loading/external objects has been viewed as a major setback to its structural applications. This phenomenon has triggered much research interest, to study the behaviour of composites under varied impact loading. ${ }^{6-9}$ Among some of these researches reported earlier are, Daniel et al. ${ }^{10}$ reported their experimental studies on the low-velocity impact behaviour of composite sandwich panel consisting of woven carbon/epoxy face-sheets and a PVC foam core on which they determined the effectiveness of predicting indentation behaviour of a sandwich panel. Hosur et al. ${ }^{11}$ reported on the impact response of woven carbon/epoxy laminate under varied environmental condition; cold-dry and cold-moist. The focus of their research was the comparison of impact parameters like peak load, time to peak load, deflection at peak load, and absorbed energy of different types of hybrid face-sheets. Some other research works with similar interest are reported in. ${ }^{12-21}$

Though significant research works have been carried out on the subject matter however, the combination of Bombyx mori with coremat is a novel idea. Fundamental investigations are needed to ascertain its capabilities in term of load carriability, energy attenuation and damage fragmentation. The current investigation present Coremat core which possess good mechanical properties and has been well investigated as the core material and woven Bombyx mori natural silk reinforced epoxy composite as face-sheet/skin. Woven Bombyx mori natural silk was considered because of its mechanical properties. ${ }^{3,22-24}$ The focus of this investigation centred on understanding the damage progress through thickness of the sandwich material, by comparing the load carriability, energy capability and physical examinations of fractured cross-sections. This research work is informed by the quest to improve impact damage-resistance of sandwich structures.

\section{Experimental studies}

\section{Materials specification}

Tables $1-3$, showed the material property specification of the materials used in this research work. The materials used were: Resin was epoxy, type (DER 331); Curing agent was: Jointmine hardener, type (905-35); Core: was Coremat; and Bombyx mori plain woven natural silk fabric. All materials excerpt Bombyx mori were supplied by Dk Composites Maleka. Plain woven Bombyx mori natural silk fabric was supplied by Loxevi Silk Indonesia.

\section{Sandwich Specimen Fabrication}

The sandwich composite specimens were prepared via hand-layup method. This method provided high quality composite samples panel with minimal defects. To fabricate the sandwich samples, Coremat core materials was sandwiched in-between B.mori WNS/ Epoxy face-sheet of $1.5 \mathrm{~mm}$ thicknesses. Special cares were taken to 
ensure that correct amount of epoxy was used in addition to being evenly spread out. The vacuum bagging was carefully spread over the sample; rubber squeeze was used to remove the extra epoxy and trapped air. The composite panels were placed in a hydraulic press at a room temperature and pressure of $10 \mathrm{bar}$ for $2 \mathrm{hr}$. After being taken out from the hydraulic press, the panels were left to cure at a room temperature for $22 \mathrm{~h}$. Finally, the panels were cut into the standard drop weight specimen size of $100 \times 100$ using a diamond cuter Figures 1-3 showed the materials and schematics diagram of the lamination process.

Table I Properties of DER 33I epoxy

\begin{tabular}{llllll}
\hline Materials & Density $\left(\mathbf{k g} / \mathbf{m}^{3}\right)$ & $\begin{array}{l}\text { Compressive strength } \\
(\mathbf{M P a})\end{array}$ & $\begin{array}{l}\text { Tensile strength } \\
(\mathbf{M P a})\end{array}$ & Cure time (hr) & Cure temperature $\left({ }^{\circ} \mathbf{C}\right)$ \\
\hline Epoxy DER 331 & 1084 & 131 & 63.6 & $9-12$ & 23.9 \\
\hline
\end{tabular}

Table 2 Properties of Bombyx mori plain woven natural silk fabric

\begin{tabular}{llllll}
\hline Materials & Density $\left(\mathbf{K g} / \mathbf{m}^{3}\right)$ & Thickness $(\mathbf{m m})$ & $\begin{array}{l}\text { Modulus of elasticity } \\
\left(\mathbf{N m}^{2}\right)\end{array}$ & $\begin{array}{l}\text { Ultimate strength } \\
\left(\mathbf{N m}^{2}\right)\end{array}$ & Elongation (\%) \\
\hline Bombyx mori & 1.4 & 0.42 & 22 & 11 & 9 \\
\hline
\end{tabular}

Table 3 Properties of core material

\begin{tabular}{lllll}
\hline Materials & Mat. Destiny $\left(\mathbf{k g} / \mathbf{m}^{\mathbf{3}}\right)$ & Comp. strength (MPa) & Tensile strength (MPa) & Shear strength (MPa) \\
\hline Coremat & 48 & 1.1 & 2 & 0.9 \\
\hline
\end{tabular}
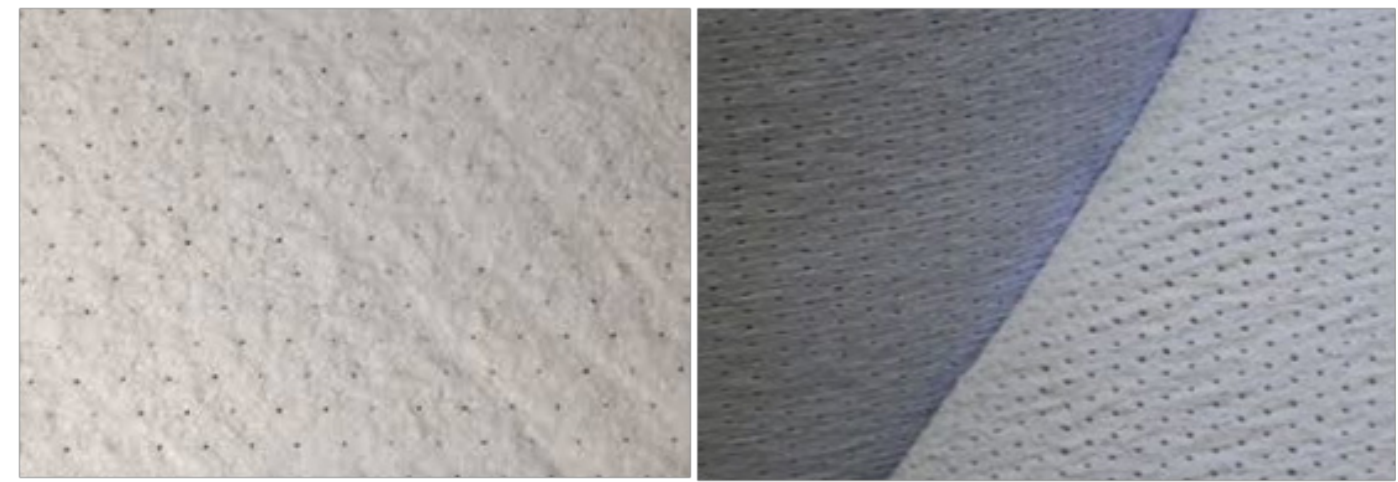

Figure I Coremat core material
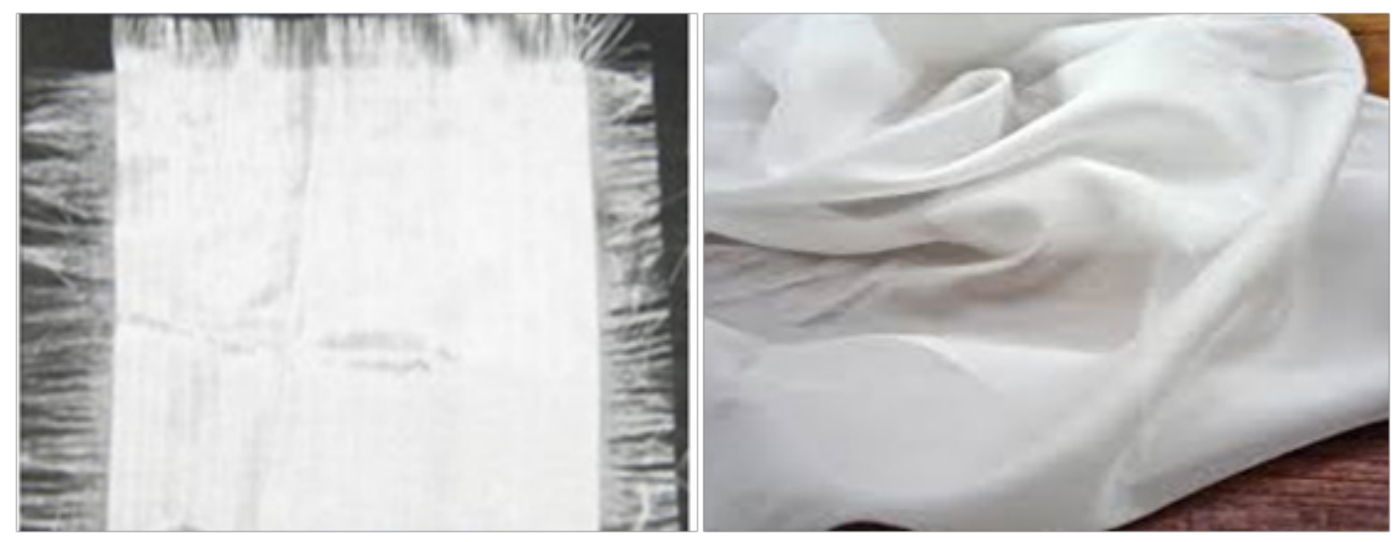

Figure 2 Plain woven Bombyx mori silk fibre- face- skin

\section{Sample specimen}

The actual size of the specimen was 100 by $100(\mathrm{~mm})$ square panel, shown in Figure 3. Three specimens were tested in each impact load category and the average values of the results were recorded.

\section{Impact testing}

The drop-weight impact testing was instrumented to measure impactor load and displacement during the impact event. This tests were performed using an instrumented drop weight testing system 
(Instron-Dynatup $9250 \mathrm{HV}$ ) Figure 4. This system is suitable for a wide variety of applications requiring low to high impact energies. The shape of the striker used was hemispherical and the size was $12.7 \mathrm{~mm}$ diameter. It was assumed to be perfectly rigid. The testing machine has a force transducer with capacity of $22.24 \mathrm{kN}$. The total mass of the impactor used was $5.1 \mathrm{~kg}$ and the impact velocity ranges from $1.95 \mathrm{~m} / \mathrm{s}-4.07 \mathrm{~m} / \mathrm{s}$. The composite specimen with dimensions of $100 \mathrm{~mm}$ by $100 \mathrm{~mm}$ was clamped via a hydro operated clamp on a fixture along a circumference having a $76.2 \mathrm{~mm}$ Diameter. The main reason behind the choice of an instrumented drop weight impact testing machine for this study was based on its ability to simulate closer to real-life impact conditions.

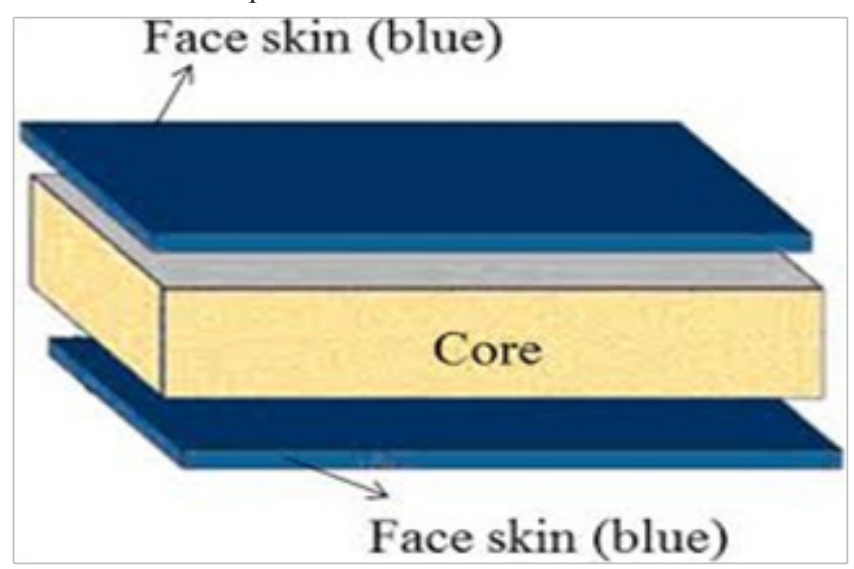

Figure 3 Schematic diagram of the sandwich composite plate specimen

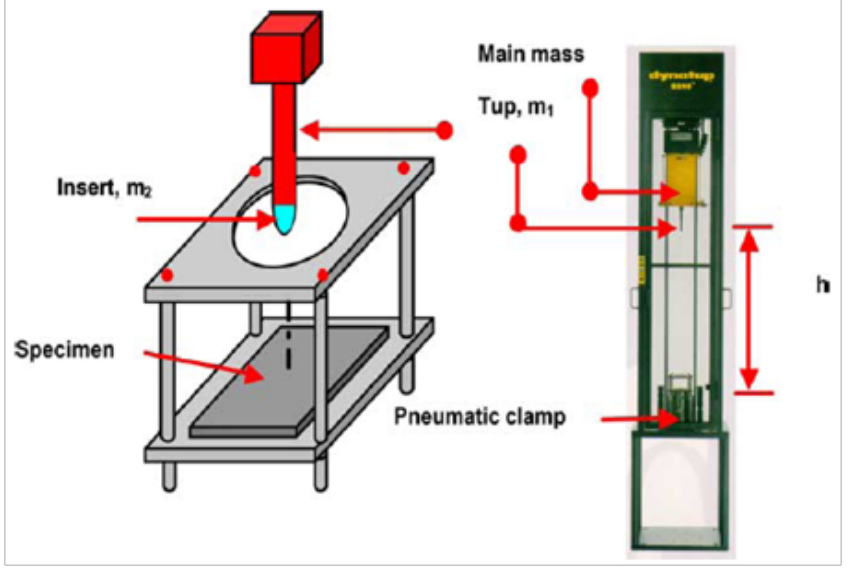

Figure 4 Schematics diagram of the experimental set-up

\section{Results and discussion}

\section{The response of composite panel on increasing impact load}

Figure 5 depicts the response of the composite panel to the increasing striking impact loads. The values and their corresponding locations were compared for 32J, 48J, and 64J impact load. Comparison of these values will help to establish fracture resistances and rate of energy attenuation as the impact load increases. From the displayed graph, all the profiles increased linearly to some points before change in directions were observed. This change in direction is believed to signify the initiation of internal damages on the composite material, this type of damages are usually matrix crack, or other forms of internal damages like delamination, which most often are invisible during physically examined. This kind of damages though may be unnoticed, causes reduction in the material stiffness and pose failure threats which may be catastrophic. Once there exists an internal damage or penetration in the specimen, absorption capability consequently reduced and non-linear progression is observed, the profiles showed different point of internal damage or pick load. The graph showed that the energy absorption capability of the composite reduced with increasing impact load.

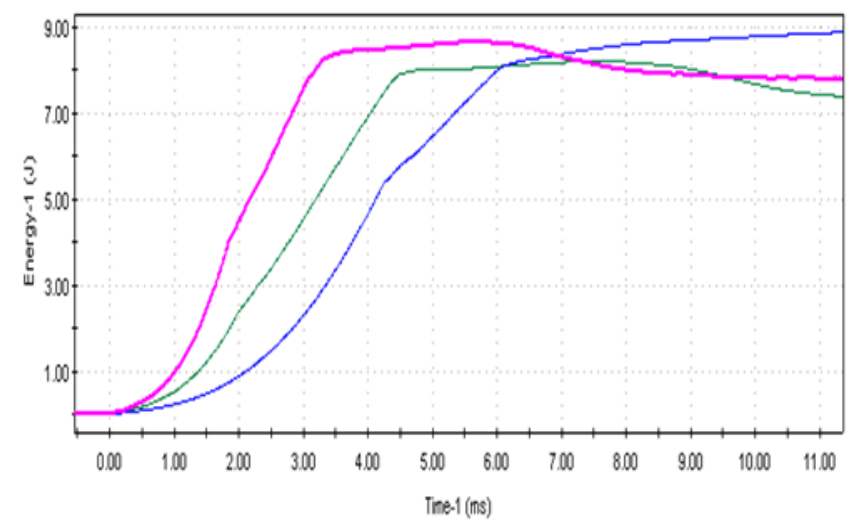

Figure 5 Energy vs Time profile

\section{The response of composite panels on impact load deflection}

Figure 6 shows the response of composite panel on impact load deflection. Deflections on the composite materials indicate changes in stiffness which induces structural degradation on the composite structure. The figure compares the amount of deflection on the composite pane as the impact load increases. From the displayed profiles it was very clear that degradation of composite specimens happened independently at different points. This phenomenon was attributed to the increasing impact load.

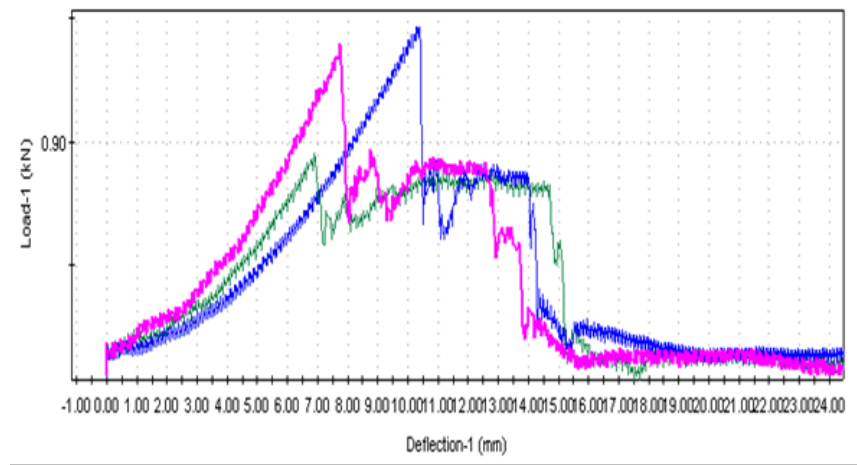

Figure 6 Deflection vs Load profile

\section{Comparison of the profiles}

Figure 7 compares deflection/energy/load profiles. Energy absorbed by the specimen without failing, is the energy through to the peak load point. It is assumed that the energy up to the peak load point is absorbed through elastic deformation, all other energies absorbed 
beyond this point is assumed to be absorbed through the creation of damages. Therefore, total absorbed energy includes energies absorbed through creation of damages. The total absorbed energy under 32J impact load was $15.2 \mathrm{~J}$, under $48 \mathrm{~J}$ was $12.8 \mathrm{~J}$ and $64 \mathrm{~J}$ impact loads was $10.8 \mathrm{~J}$ respectively. The differences in structural absorbed energy i.e. (energy absorbed by the composite material before any changes in stiffness occurred) ranged from 1.0-5.0J.

\section{Failure mechanism and damage fragmentation}

Several damage modes have been observed under the three impact loads categories in this experiment. In Figure 8, specimen was stroked by $32 \mathrm{~J}$ impact load, damage modes were detected as matrix cracks and fibre fracture. There was no penetration damage from the contact point (top surface), the cross-section photos showed the extent of damage that was incurred internally by the composite panel; this includes internal cracks and deformation. In Figure 9, the impact load was increased to $48 \mathrm{~J}$. The pattern of surface damage was a spherical
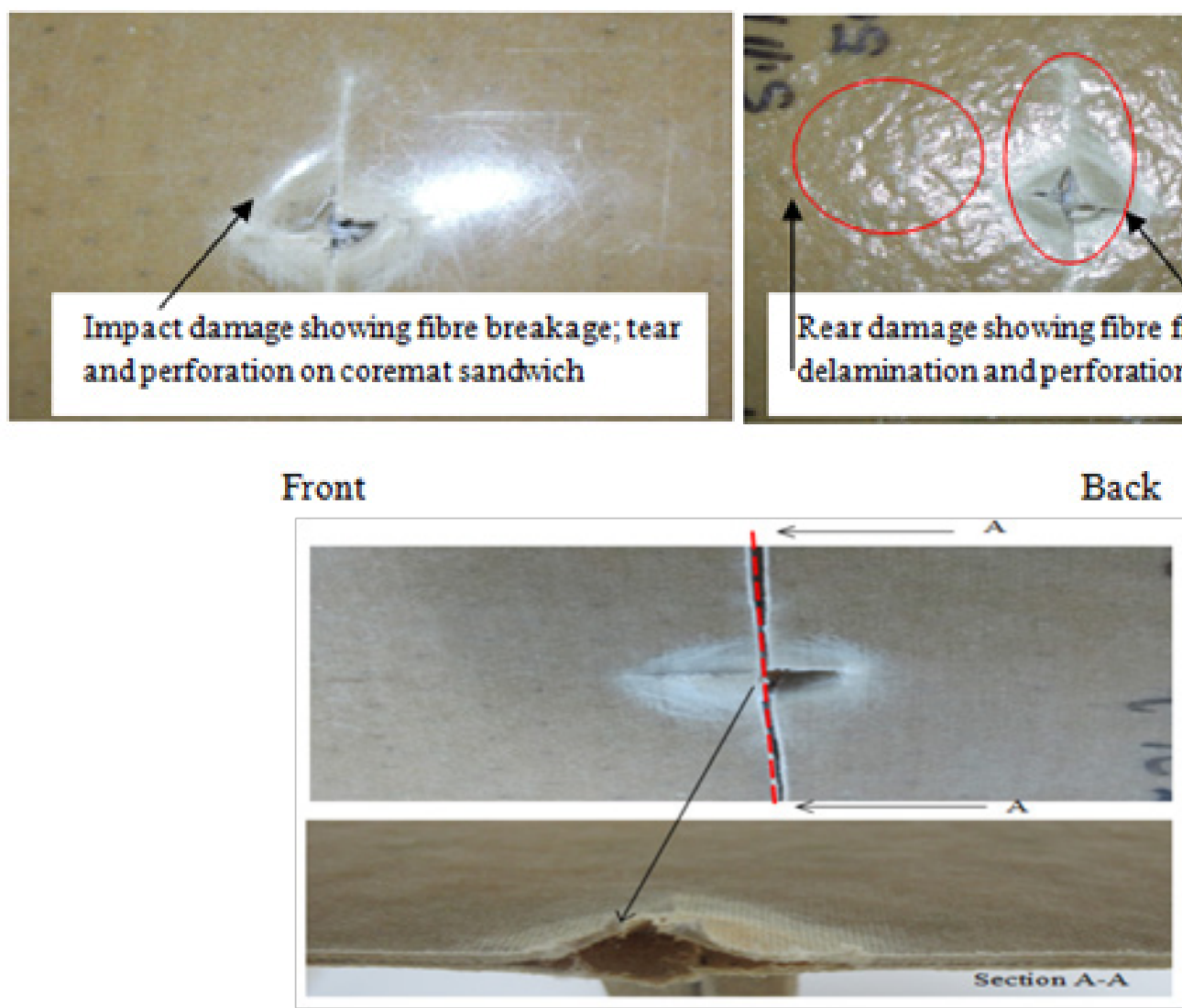

Figure 8 Surface and internal impact damage under 32J impact load

\section{Conclusion}

An experimental investigation has been carried out on the impact response of woven natural fibre/epoxy sandwiched Coremat composite. Comparison of the load bearing capabilities, rate of energy absorption, damage fragmentation and failure mechanism of WNS/ Epoxy sandwich composite panels under varied drop weight impact load was assessed. From the results, these conclusions were drawn: absorption energy capability decreased with increasing impact load. shape; visible perforation damage was also noticed. Cross-sectional examination of the panel show increase in internal damage compared with the previous. In Figure 10 which has $64 \mathrm{~J}$ impact load, the dominant damage was perforations accompanied by fibre breakage, matrix cracks and delaminations. In comparison, damage severity and fragmentation increased with increased impact load

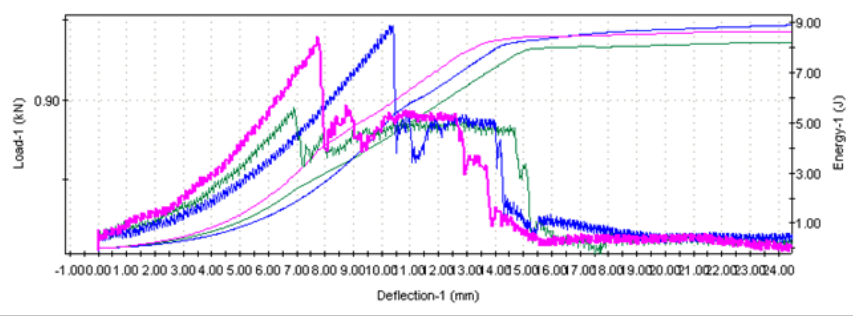

Figure 7 Deflection vs Load vs Energy profiles

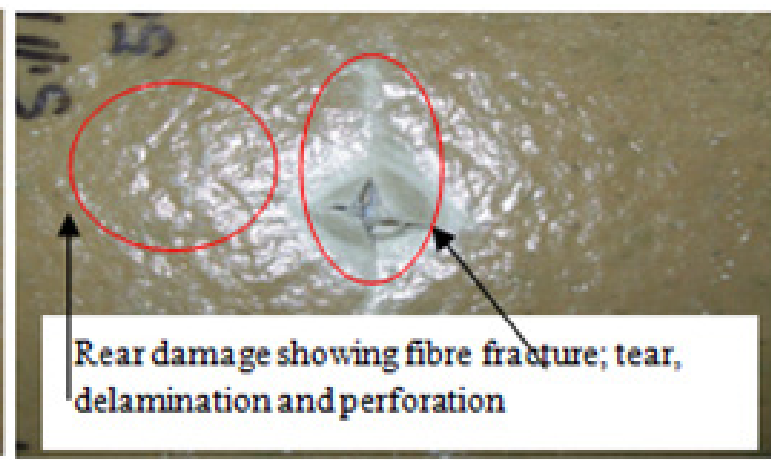

Back
There was deflection on each impact load configuration, though the values between them were negligible. Visual examination of the composite specimen however, show that damage areas and severity increased with increase in impact load, suggesting that most of the energies absorbed under higher impact loads were absorbed through the formation of damages. Findings of this work are expected to be useful in understanding the impact behaviour of woven natural silk sandwiched Coremat composite panels under varied impact load. 

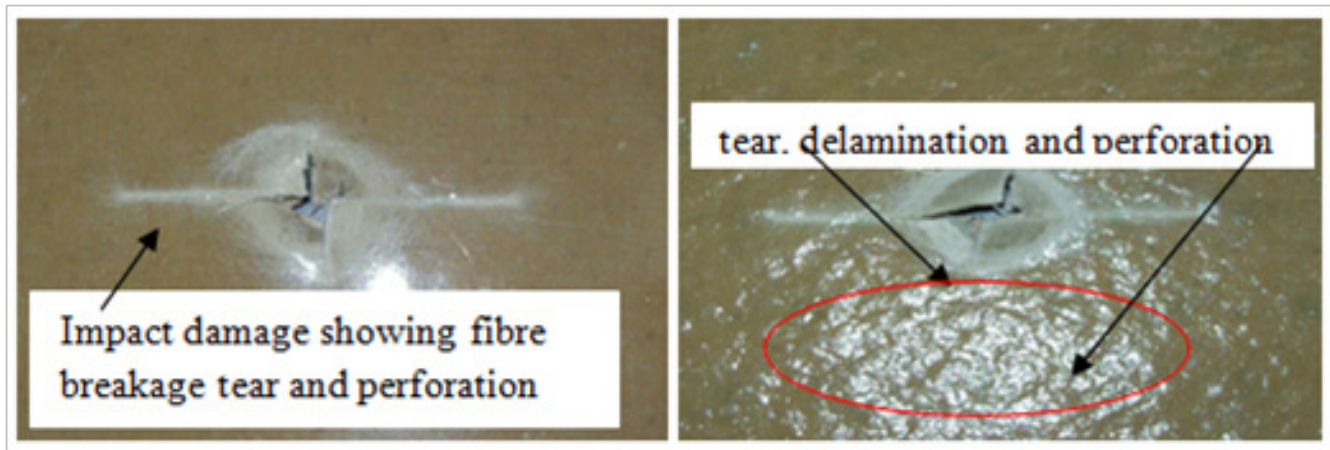

Front

Back
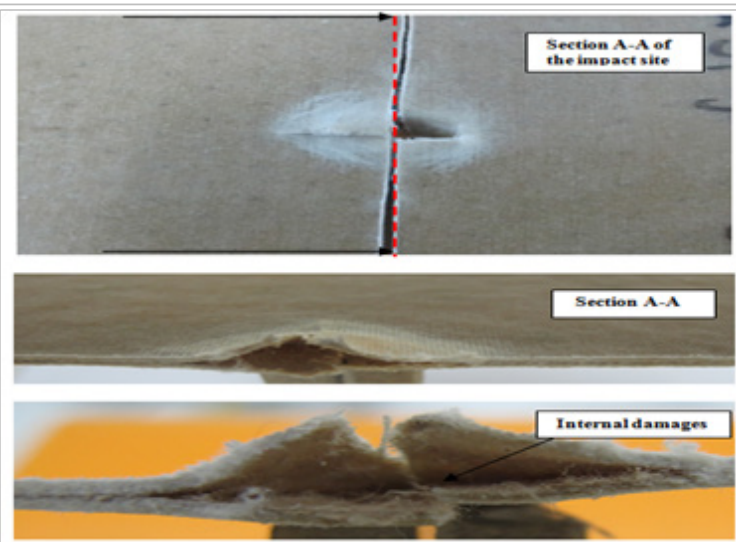

Figure 9 Surface and internal impact damage under 48j impact load
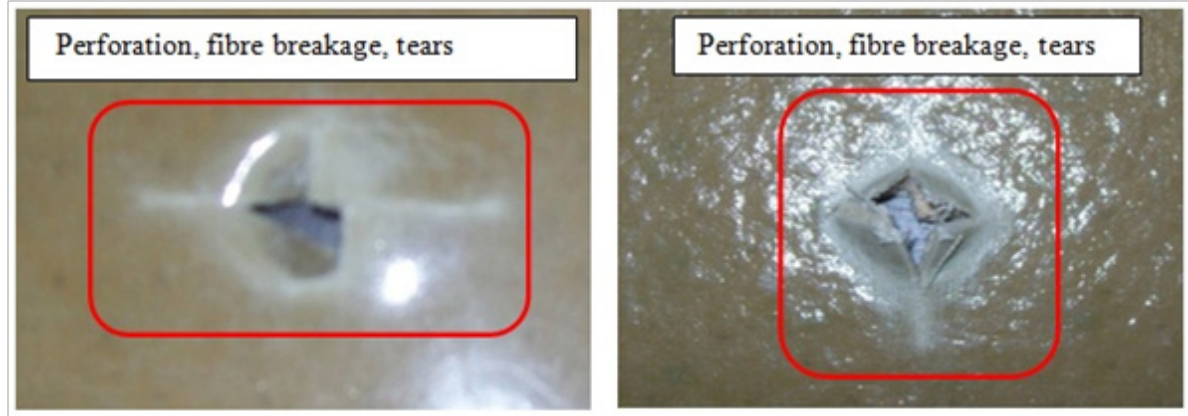
Front
back

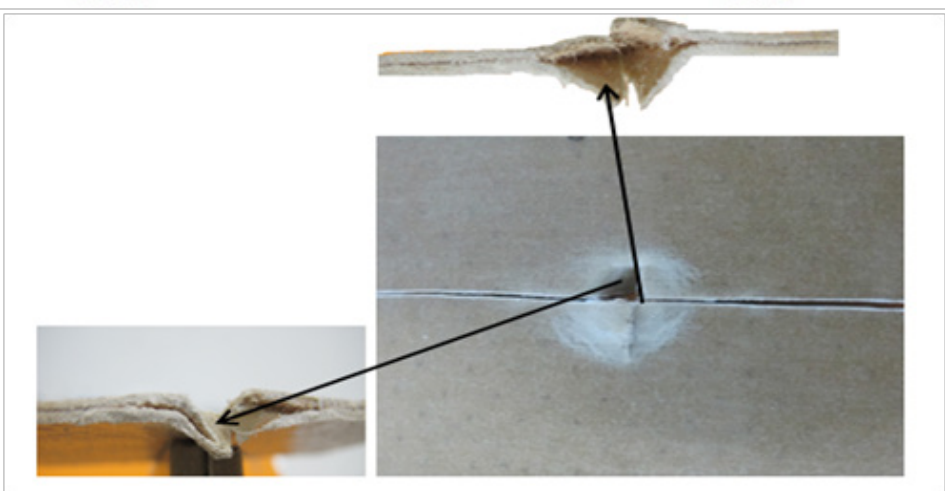

Figure 10 Surface and internal impact damage under 64J impact load 


\section{Acknowledgments}

Financial support for this research work was provided by MOSTI (project code 03-01-02-SF0075). Partial financial support by Universiti Kebangsaan Malaysia (The National University of Malaysia) Bangi is also gratefully acknowledged.

\section{Conflict of interest}

Authors declare there is no conflict of interest in publishing the article

\section{References}

1. Othman AR, Barton DC. Failure initiation and propagation characteristics of honeycomb sandwich composites. Composite Structures. 2008;85(2):126-138.

2. Mines RAW, Jones N. Approximate elastic-plastic analysis of the static and impact behaviour of polymer composite sandwich beams. Composites. 1995;26(12):803-814.

3. Ataollahi S, Taher ST, Eshkoor RA, et al. Energy absorption and failure response of silk/epoxy composite square tubes: Experimental. Composites Part B: Engineering. 2012;43(2):542-548.

4. Dhakal HN, Arumugam V, Aswinraj A, et al. Influence of temperature and impact velocity on the impact response of jute/UP composites Polymer Testing. 2014;35:10-19.

5. Ude AU, Ariffin AK, Azhari CH. An experimental investigation on the response of woven natural silk fiber/epoxy sandwich composite panels under low velocity impact. Fibers \& Polymers. 2013;14(1):127-132.

6. Ude AU, Ariffin AK, Azhari $\mathrm{CH}$. Impact damage characteristics in reinforced woven natural silk/epoxy composite face-sheet and sandwich foam, coremat and honeycomb materials. International $J$ Impact Engineering. 2013;58:31-38.

7. Yuanjian $T$, Isaac DH. Impact and fatigue behaviour of hemp fibre composites. Composites Science \& Technology. 2007;67(15-16):3300-3307.

8. Zhao H, Elnasri I, Girard Y. Perforation of aluminium foam core sandwich panels under impact loading-An experimental study. International J Impact Engineering. 2007;34(7):1246-1257.

9. Dear JP, Lee H, Brown SA. Impact damage processes in composite sheet and sandwich honeycomb materials. International J Impact Engineering. 2005;32(1-4):130-154.

10. Daniel IM, Abot JL, Schubel PM, et al. Response and Damage Tolerance of Composite Sandwich Structures under Low Velocity Impact. Experimental Mechanics. 2012;52(1):37-47.
11. Hosur MV, Jain K, Chowdhury F, et al. Low-velocity impact response of carbon/epoxy laminates subjected to cold-dry and cold-moist conditioning. Composite Structures. 2007;79(2):300-311.

12. Anderson T, Madenci E. Experimental investigation of low-velocity impact characteristics of sandwich composites. Composite Structures. 2000;50(3):239-247.

13. Atas C, Sevim C. On the impact response of sandwich composites with cores of balsa wood and PVC foam. Composite Structures. 2010;93(1):40-48.

14. Caprino G, Teti R. Impact and post-impact behavior of foam core sandwich structures. Composite Structures. 1994;29(1):47-55.

15. Gustin J, Joneson A, Mahinfalah M, et al. Low velocity impact of combination Kevlar/carbon fiber sandwich composites. Composite Structures. 2005;69(4):396-406.

16. Reis PNB, Ferreira JAM, Santos P, et al. Impact response of Kevlar composites with filled epoxy matrix. Composite Structures. 2012;94(12):3520-3528.

17. Sarasini F, Tirillò J, Ferrante L, et al. Drop-weight impact behaviour of woven hybrid basalt-carbon/epoxy composites. Composites Part B: Engineering. 2014;59:204-220.

18. Sarasini F, Tirillò J, Valente M, et al. Effect of basalt fiber hybridization on the impact behavior under low impact velocity of glass/basalt woven fabric/epoxy resin composites. Composites Part A: Applied Science and Manufacturing. 2013;47:109-123.

19. Schubel PM, Luo J-J, Daniel IM. Impact and post impact behavior of composite sandwich panels. Composites Part A: Applied Science and Manufacturing. 2007;38(3):1051-1057.

20. Wu CL, Sun CT. Low velocity impact damage in composite sandwich beams. Composite Structures. 1996;34(1):21-27.

21. Xia F, Wu X-q. Study on impact properties of through-thickness stitched foam sandwich composites. Composite Structures. 2010;92(2):412-421.

22. Pérez-Rigueiro J, Viney C, Llorca J, et al. Mechanical properties of silkworm silk in liquid media. Polymer. 2000;41(23):8433-8439.

23. Oshkovr SA, Eshkoor RA, Taher ST, et al. Crashworthiness characteristics investigation of silk/epoxy composite square tubes. Composite Structures. 2012;94(8):2337-2342.

24. Eshkoor RA, Ude AU, Oshkovr SA, et al. Failure mechanism of woven natural silk/epoxy rectangular composite tubes under axial quasistatic crushing test using trigger mechanism. International J Impact Engineering. 2014;64:53-61. 